\title{
A Kinetic Model of Nonenzymatic RNA Polymerization by Cytidine- 5'-phosphoro-2-aminoimidazolide
}

\author{
Travis Walton ${ }^{\circledR}$ and Jack W. Szostak*® \\ Howard Hughes Medical Institute, Department of Molecular Biology, and Center for Computational and Integrative Biology, \\ Massachusetts General Hospital, Boston, Massachusetts 02114, United States
}

\section{Supporting Information}

ABSTRACT: The nonenzymatic polymerization of RNA may have enabled copying of functional sequences during the origin of life. Recent progress utilizing 5'-phosphoro-2-aminoimidazole activation has reinvigorated the possibility of using nonenzymatic RNA polymerization for copying arbitrary sequences. However, the reasons why 2-aminoimidazole (AI) is a superior activation group remain unclear. Here we report that the predominant mechanism of polymerization using cytidine- 5 '-phosphoro-2aminoimidazolide ( $\left.\mathrm{Cp}^{*}\right)$ involves a 2 -aminoimidazolium-bridged dinucleotide $(\mathrm{Cp} * \mathrm{pC})$ intermediate. To explore the role of this intermediate, we first identify and quantify four reactions involving the synthesis and breakdown of $\mathrm{Cp}^{*} \mathrm{pC}$ that occur in the absence of the primer-template duplex. We then analyze the
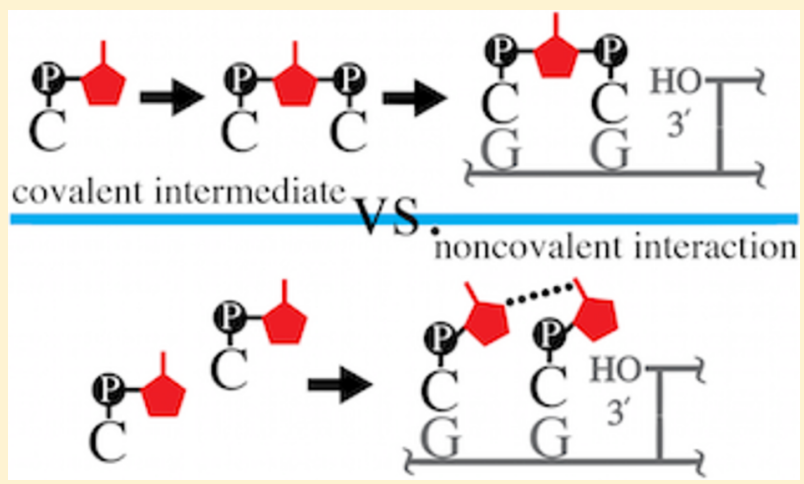
dependence of the rate of polymerization on the concentration of the $\mathrm{Cp} * \mathrm{pC}$ intermediate in the presence and absence of the competitive inhibitor $\mathrm{Cp}$. We also show that the contribution of the monomer $\mathrm{Cp}^{*}$ to the polymerization rate is negligible under our primer extension conditions. Finally, we use the experimentally determined rate constants of these reactions to develop a kinetic model that helps explain the changing rate of nonenzymatic RNA polymerization over time. Our model accounts for the concentration of $\mathrm{Cp}^{*} \mathrm{pC}$ formed by $\mathrm{Cp}^{*}$ under primer extension conditions. The model does not completely account for the decline in polymerization rate observed over long times, which indicates that additional important inhibitory processes have not yet been identified. Our results suggest that the superiority of 2 aminoimidazole over the traditional 2-methylimidazole activation is mostly due to the higher level of accumulation of the imidazolium-bridged intermediate under primer extension conditions.

$\mathrm{T}$ he RNA world hypothesis proposes that early stages of life may have involved the self-replication of RNA oligonucleotides. However, experimental demonstration of RNA selfreplication has been extremely difficult, leading some to abandon this hypothesis and suggest alternative scenarios. ${ }^{1,2}$ Both the lack of regioselectivity and the limited template generality of nonenzymatic RNA polymerization have been cited as major obstacles to the RNA world. In addition, the prebiotic formation of the canonical RNA nucleosides through glycosylation of ribose is very inefficient, which has raised questions about the availability of RNA in prebiotic environments. ${ }^{3}$

Recent work has revived the hypothesis of a primarily RNAbased foundation to the origin of life. First, the synthesis of both ribonucleotides and amino acids from cyanide and other simple molecular precursors offers a plausible set of prebiotic chemical reactions leading to both RNA and peptides. ${ }^{4}$ Second, potential solutions to several steps in the nonenzymatic replication of RNA have been proposed. For example, replacing uridine with 2-thiouridine increases the rate of templatedirected nonenzymatic polymerization by increasing the affinity of monomers for the template. ${ }^{5,6}$ In addition, the reannealing of a large RNA duplex has been greatly slowed by increased solvent viscosity and RNA secondary structure, allowing information transfer.

Nevertheless, the one-pot synthesis of a functional RNA sequence through template-directed nonenzymatic polymerization has not been achieved and remains a critical goal for establishing a physicochemical approach to primitive genetic inheritance. Recent progress in nonenzymatic template-directed RNA polymerization has utilized RNA monomers combined with downstream oligomers, all activated with a substituted imidazole group on the $5^{\prime}$-phosphate. ${ }^{8,9}$ This system iteratively extends the $3^{\prime}$ end of a primer to synthesize a complementary strand, even over difficult mixed-template sequences. Furthermore, the increased length and yield of primer extension reactions have been observed using 2-aminoimidazole instead of 2-methylimidazole activation. ${ }^{9}$

Continued improvement of nonenzymatic RNA polymerization is likely to benefit from a detailed understanding of the chemical mechanism. Our recent report on the kinetics of

Received: August 16, 2017

Revised: October 9, 2017

Published: October 12, 2017 
primer extension by 2-methylimidazole-activated monomers suggested that the first step of the mechanism involves the formation of a 2-methylimidazolium-bridged dinucleotide. ${ }^{10}$ Upon subsequent binding to the template, this dimer intermediate reacts with the $3^{\prime}$-hydroxyl of the primer, extending it by one nucleotide and releasing an activated monomer as the leaving group. This mechanism contrasts with a previous proposal that two monomers bind the template such that the downstream monomer catalyzes primer extension through noncovalent interactions with the upstream monomer. ${ }^{8,11}$ Recent thermodynamic studies have cast doubt on the latter model because the affinity of the monomer in the downstream $(+2)$ position is relatively low. ${ }^{12}$ In addition, crystallographic studies of monomers bound to a template revealed a variety of conformations, some of which are not productive for polymerization reactions. ${ }^{13}$ In contrast, structural studies of GpppG, a stable analogue of the intermediate, suggest that the imidazolium bridge may help to preorganize the reaction center for polymerization. ${ }^{14}$ However, the relative contribution of each of these two mechanisms to the rate of primer extension has not yet been clarified.

Kinetic analysis has been a powerful tool for understanding the reaction mechanism of primer extension systems. For instance, kinetic studies have elucidated the mechanism of 2MeImpG hydrolysis, a simplified model of template-directed polymerization. ${ }^{15,16}$ In addition, two earlier kinetic models identified key determinants of the yield and rate in nonenzymatic RNA polymerization that depend on the particular system studied. Kanavarioti et al. ${ }^{17,18}$ account for the synthesis of poly-G catalyzed by poly-C through the quantification of three reactions: monomer hydrolysis, off-template oligomerization, and template-directed primer extension. Also, Kervio et al. ${ }^{19}$ have shown that the hydrolysis of 1-hydroxybenzotriazoleactivated monomers and competitive inhibition by inactivated monomers are the main limitations for primer extension in that system. However, neither of these models can likely be applied to primer extension by nucleotides activated by 2 -aminoimidazole because they do not account for the potential kinetic effects of the imidazolium-bridged dinucleotide intermediate.

Here, we present a kinetic model of nonenzymatic RNA polymerization by cytidine- 5 ' -phosphoro-2-aminoimidazolide (Cp*) (Chart 1). Our results show that the predominant mechanism of polymerization involves a dinucleotide intermediate in which the two 5 -phosphates are bridged by a 2 aminoimidazolium moiety $(\mathrm{Cp} * \mathrm{pC})$. To understand the factors that control the concentration of the intermediate, we studied the kinetics of four reactions that affect $\mathrm{Cp}^{*} \mathrm{pC}$ levels. We first examined the formation of $\mathrm{Cp}^{*} \mathrm{pC}$ and 2 -aminoimidazole (AI)

Chart 1. Chemical Structure and Cartoon Representation of the Molecules Investigated in This Study
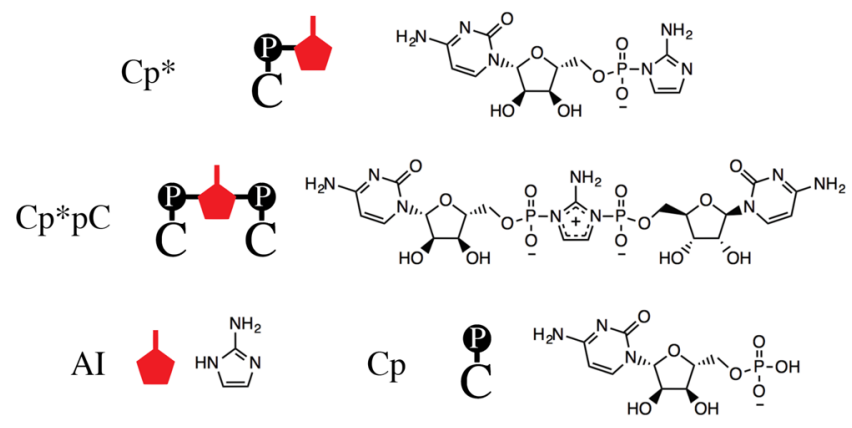

from $\mathrm{Cp}^{*}$ under primer extension conditions by ${ }^{31} \mathrm{P}$ nuclear magnetic resonance (NMR), as well as the reverse process in which $\mathrm{AI}$ reacts with $\mathrm{Cp} \mathrm{p}^{*} \mathrm{pC}$ to form $\mathrm{Cp}$ *. We also measured the rates of hydrolysis of the intermediate $\mathrm{Cp}^{*} \mathrm{pC}$ and the monomer $\mathrm{Cp}^{*}$. To understand the relationship between the concentration of $\mathrm{Cp}^{*} \mathrm{pC}$ and nonenzymatic polymerization, we analyzed the rate of primer extension by $\mathrm{Cp}^{*} \mathrm{pC}$ and competitive inhibition by cytidine $5^{\prime}$-monophosphate $(\mathrm{Cp})$ using Michaelis-Menten kinetics. We combined our empirical rate constants into a kinetic model that relates a series of offtemplate reactions, including synthesis and decay of $\mathrm{Cp}^{*} \mathrm{pC}$, to template-directed primer extension. Our model accounts for the long-term behavior of the off-template reactions and for observations of primer extension rate over the first $2 \mathrm{~h}$. At longer times, additional uncharacterized effects lead to a gradual slowing of the rate of primer extension. Our results suggest that the improved polymerization yield of 2 -amino- versus 2methylimidazole-activated monomers is likely due to the higher level of accumulation of the intermediate under primer extension conditions.

\section{MATERIALS AND METHODS}

All reagents were purchased from Sigma-Aldrich unless specified. 2-Aminoimidazole hemisulfate was purchased from Combi-Blocks, Inc. All other exceptions are specified in our previous report. ${ }^{10}$ All syntheses involving the attachment of imidazole to the $5^{\prime}$-phosphate have been previously reported. ${ }^{9,10}$

With the following exceptions, all nonenzymatic primer extension reactions were performed as previously described. ${ }^{10}$ For all reactions, the template concentration is $3 \mu \mathrm{M}$ and the primer concentration is $2 \mu \mathrm{M}$. Except where noted below, primer extension occurs in $90 \mathrm{mM} \mathrm{MgCl}$ and $90 \mathrm{mM}$ Tris $(\mathrm{pH}$ 8.3-8.4). In Figure 5b, the reactions including $45 \mathrm{mM} \mathrm{Cp}$ used $160 \mathrm{mM}$ Tris to improve $\mathrm{pH}$ buffering. Also, in Figure 6e, primer extension occurs in $100 \mathrm{mM} \mathrm{MgCl}$ and $100 \mathrm{mM}$ Tris ( $\mathrm{pH} 8.3-8.4)$.

All NMR spectra were recorded on a Varian INOVA 400 $\mathrm{MHz}$ NMR spectrometer at $25{ }^{\circ} \mathrm{C}$. For all kinetic analyses, samples were prepared in $\mathrm{H}_{2} \mathrm{O}$, and a coaxial insert containing $\mathrm{D}_{2} \mathrm{O}$ was used for locking. This eliminates possible solvent isotope effects. All peak assignments were confirmed by addition of standards. For characterization, samples were prepared in $\mathrm{D}_{2} \mathrm{O}$, and a coaxial insert was not used. Peaks are referenced to internal trimethyl phosphate $(\delta 0.00)$ for ${ }^{31} \mathrm{P}$ NMR, internal acetone $(\delta 30.89)$ for ${ }^{13} \mathrm{C}$ NMR, and HOD $(\delta$ 4.79) for ${ }^{1} \mathrm{H}$ NMR. NMR spectra of $\mathrm{Cp}^{*} \mathrm{pC}$ characterization are included (Figure S1).

Cp*pC: ${ }^{1} \mathrm{H}$ NMR (400 MHz) $\delta 7.66(\mathrm{~d}, J=7.6 \mathrm{~Hz}, 1 \mathrm{H})$, $6.96(\mathrm{~m}, 1 \mathrm{H}), 6.03(\mathrm{~d}, J=7.5 \mathrm{~Hz}, 1 \mathrm{H}), 5.85(\mathrm{~d}, J=3.2 \mathrm{~Hz}$, $1 \mathrm{H}), 4.12(\mathrm{~m}, 5 \mathrm{H}) ;{ }^{31} \mathrm{P}$ NMR $(161 \mathrm{MHz}) \delta-12.84(\mathrm{~s}) ;{ }^{13} \mathrm{C}$ NMR (100 MHz) $\delta 166.58(\mathrm{~s}), 157.90(\mathrm{~s}), 150.91(\mathrm{t}, J=7.1$ $\mathrm{Hz}$ ), 141.62 (s), 116.83 (dd, $J=3.7,6.7 \mathrm{~Hz}$ ), 96.77 (s), 90.73 (s), $82.19(\mathrm{~d}, J=8.5 \mathrm{~Hz}), 74.68(\mathrm{~s}), 69.49(\mathrm{~s}), 66.16(\mathrm{~d}, J=5.8$ $\mathrm{Hz})$; calcd $m / z-692.12$, observed $m / z-692.1$.

All NMR spectra were analyzed and quantified using MestReNova software. All kinetic analyses were performed using Microsoft Excel and Prism 7. Parameter fitting of the offtemplate reactions was performed using code written in $\mathrm{R}$. All values are presented as means \pm the standard deviation unless specified otherwise. 


\section{RESULTS AND DISCUSSION}

Cp* Monomers Self-React To Form Cp*pC in Primer Extension Buffer. We began our analysis of $\mathrm{Cp}^{*}$ by determining whether dinucleotide intermediate $\mathrm{Cp} \mathrm{p}^{*} \mathrm{pC}$ can form in primer extension buffer (Figure 1a). On the basis of

a.

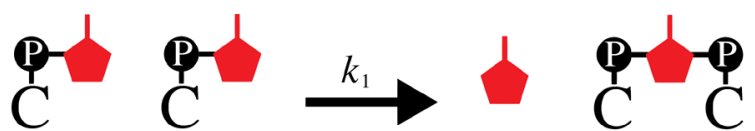

b.

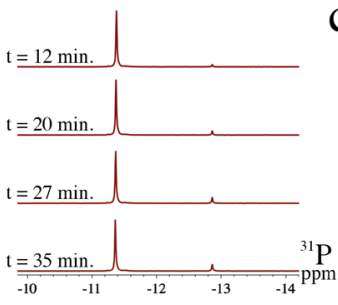

c.

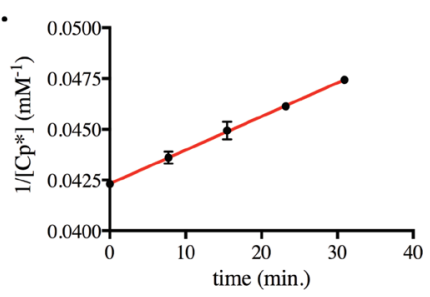

Figure 1. Measuring the reaction of two $\mathrm{Cp}^{*}$ monomers to form $\mathrm{AI}$ and $\mathrm{Cp}^{*} \mathrm{pC}$. (a) Schematic of the reaction being measured for calculation of rate constant $k_{1}$. (b) ${ }^{31} \mathrm{P}$ NMR spectra of $24 \mathrm{mM} \mathrm{Cp} *$ incubated in primer extension buffer over time. Peaks at $-11.38 \mathrm{ppm}$ correspond to $\mathrm{Cp}^{*}$ and $-12.86 \mathrm{ppm}$ to $\mathrm{Cp}^{*} \mathrm{pC}$. (c) Analysis of the ${ }^{31} \mathrm{P}$ NMR spectra at $24 \mathrm{mM} \mathrm{Cp} *$ in triplicate by a second-order rate plot. Error bars indicate $\pm \mathrm{SD}(n=3)$. The slope is equal to $2 k_{1}$.

previous studies of 2-MeImpG, we expected that the $\mathrm{Mg}^{2+}$ concentration and $\mathrm{pH}$ would likely affect our observations. ${ }^{15}$ Recent studies of nonenzymatic RNA polymerization have used 50-200 $\mathrm{mM} \mathrm{MgCl}_{2}$ and $\mathrm{pH} 8-9 .^{8-10}$ For these experiments, we used $100 \mathrm{mM} \mathrm{MgCl}_{2}$ and $100 \mathrm{mM}$ Tris ( $\mathrm{pH} \mathrm{8.3-8.4)} \mathrm{as} \mathrm{the}$ primer extension buffer.

We used ${ }^{31} \mathrm{P}$ NMR to observe the formation of $\mathrm{Cp} * \mathrm{pC}$ from $\mathrm{Cp}^{*}$ in primer extension buffer (Figure 1a). Because incubation of monomers near the $\mathrm{p} K_{\mathrm{a}}$ of the imidazole group is known to promote formation of the intermediate, solutions of $\mathrm{Cp}^{*}$ were kept at $\mathrm{pH} \sim 10$ to prevent the reaction from occurring before addition to the primer extension buffer. Incubation of $24 \mathrm{mM}$ $\mathrm{Cp}^{*}$ in primer extension buffer resulted in the time-dependent appearance of a new peak in ${ }^{31} \mathrm{P}$ NMR spectra (Figure $1 \mathrm{~b}$ ). The new peak corresponds to intermediate $\mathrm{Cp} \mathrm{p}^{*} \mathrm{pC}$, as confirmed by the addition of a synthetically prepared standard. We did not observe significant formation of $\mathrm{Cp}$ during the course of the experiment, suggesting that $\mathrm{Cp} * \mathrm{pC}$ was not immediately hydrolyzing.

Next, we determined rate constant $k_{1}$ for the reaction of two $\mathrm{Cp}^{*}$ monomers to form $\mathrm{Cp} \mathrm{p}^{*} \mathrm{C}$ and $\mathrm{AI}$ in primer extension buffer. Samples were prepared in $\mathrm{H}_{2} \mathrm{O}$ to avoid potential solvent isotope effects and concentrations measured by integration of ${ }^{31} \mathrm{P}$ NMR peaks. The formation of $\mathrm{AI}$ was not directly observed because AI does not contain a phosphorus atom. We assumed that the observed kinetics would be entirely due to the reaction of two $\mathrm{Cp}^{*}$ molecules to form $\mathrm{Cp}^{*} \mathrm{pC}$. First, we confirmed that the formation of $\mathrm{Cp}^{*} \mathrm{pC}$ does indeed follow second-order kinetics by measuring the initial rate of $\mathrm{Cp}^{*} \mathrm{pC}$ synthesis at four initial concentrations of $\mathrm{Cp}^{*}$. As expected, the initial rate of $\mathrm{Cp} * \mathrm{pC}$ synthesis increased with the square of the initial concentration of $\mathrm{Cp}^{*}$ (Figure S2). Using the 12 experiments with initial $\mathrm{Cp}^{*}$ concentrations from 15 to $40 \mathrm{mM}$, we calculated the second-order rate constant $\left(k_{1}\right)$ to be $[4.49 \pm 0.47$ (standard deviation) $] \times 10^{-3} \mathrm{~h}^{-1} \mathrm{mM}^{-1}$ and to range from 3.65 to $5.22 \times 10^{-3} \mathrm{~h}^{-1} \mathrm{mM}^{-1}$ (Figure $1 \mathrm{c}$ and Figure S3).

Al Reacts with Cp*pC To Form Two Molecules of Cp*. Having determined that intermediate $\mathrm{Cp} * \mathrm{pC}$ can form in primer extension buffer, we began to consider additional reactions that would affect the concentration of the intermediate during a primer extension experiment. We first examined the reverse of its synthetic reaction, i.e., the nucleophilic attack of $\mathrm{AI}$ on $\mathrm{Cp} \mathrm{p}^{\mathrm{pC}}$ to generate two $\mathrm{Cp}$ * monomers (Figure $2 \mathrm{a}$ ). This reaction has not been previously described or measured.

a.

a.

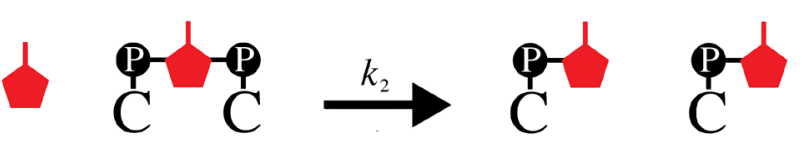

b.

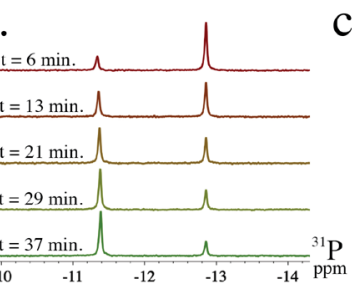

c.

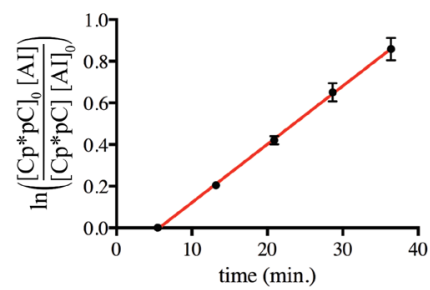

Figure 2. $\mathrm{Cp}^{*} \mathrm{pC}$ reacts with $\mathrm{AI}$ to form two molecules of $\mathrm{Cp}^{*}$. (a) Schematic of the reaction measured to determine $k_{2}$. (b) ${ }^{31} \mathrm{P}$ NMR spectra of $5 \mathrm{mM} \mathrm{Cp} * \mathrm{pC}$ and $11.5 \mathrm{mM} \mathrm{AI}$ incubated in primer extension buffer. The peaks at $-11.41 \mathrm{ppm}$ correspond to monomer $\mathrm{Cp}^{*}$ and $-12.86 \mathrm{ppm}$ to dinucleotide intermediate $\mathrm{Cp} * \mathrm{pC}$. (c) Analysis of the reaction between $5 \mathrm{mM} \mathrm{Cp} * \mathrm{pC}$ and $11.5 \mathrm{mM} \mathrm{AI}$ in a second-order kinetic plot. In the plot, $k_{2}$ is equal to the slope divided by $[\mathrm{AI}]_{0}-\left[\mathrm{Cp}^{*} \mathrm{pC}\right]_{0}$. Error bars indicate $\pm \mathrm{SD}(n=3)$.

To follow the reaction of $\mathrm{AI}$ with $\mathrm{Cp}^{*} \mathrm{pC}, 11.5 \mathrm{mM} \mathrm{AI}$ was incubated with $5 \mathrm{mM} \mathrm{Cp} * \mathrm{pC}$ in primer extension buffer, and the progress of the reaction was monitored by ${ }^{31} \mathrm{P}$ NMR spectroscopy (Figure 2b). We observed that the magnitude of the peak for $\mathrm{Cp} \mathrm{p}^{*} \mathrm{pC}$ rapidly decreased and that the magnitude of the peak for $\mathrm{Cp}^{*}$ increased over time. In addition, the concentration of $\mathrm{Cp}$ did not significantly change during the course of the reaction. This indicates that the increase in the level of $\mathrm{Cp}^{*}$ is not due to hydrolysis of $\mathrm{Cp}^{*} \mathrm{pC}$. Instead, these results indicate that $\mathrm{AI}$ reacts with $\mathrm{Cp}^{*} \mathrm{pC}$ to form two molecules of $\mathrm{Cp}^{*}$.

We measured the rate of the reaction between $\mathrm{AI}$ and $\mathrm{Cp} * \mathrm{pC}$ at five different concentrations to determine the reaction order. On the basis of the reaction order, the kinetics should be overall second-order for this reaction, with first-order for both $\mathrm{AI}$ and $\mathrm{Cp} * \mathrm{pC}$. A reaction order of $\sim 0.8$ was determined for both AI and Cp*pC (Figure S4). We suspect that the empirical determinations of the reaction order might be slight underestimations because of the technical difficulty of measuring the fast rate of the reaction. The 15 experiments with varying concentrations of 5.75-17.25 $\mathrm{mM} \mathrm{AI}$ and 2.5-7.5 $\mathrm{mM} \mathrm{Cp} * \mathrm{pC}$ were analyzed using second-order kinetic plots to calculate a $k_{2}$ of $0.238 \pm 0.020(\mathrm{SD}) \mathrm{h}^{-1} \mathrm{mM}^{-1}$ with a range of $0.190-0.271 \mathrm{~h}^{-1} \mathrm{mM}^{-1}$ (Figure 2c and Figure S5).

Cp*pC Hydrolyzes to $\mathrm{Cp}^{*}$ and $\mathrm{Cp}$. In addition to reacting with $\mathrm{AI}$, we expected that $\mathrm{Cp}^{*} \mathrm{pC}$ would also decay through hydrolysis to form $\mathrm{Cp}$ and $\mathrm{Cp}^{*}$ (Figure 3a). This reaction has been previously observed for the 2-methylimidazolium-bridged dinucleotide. ${ }^{10}$ To measure this reaction, ${ }^{31} \mathrm{P}$ NMR spectra of $5 \mathrm{mM} \mathrm{Cp} * \mathrm{pC}$ in primer extension buffer were 


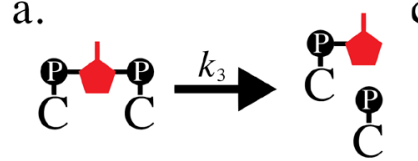

b.
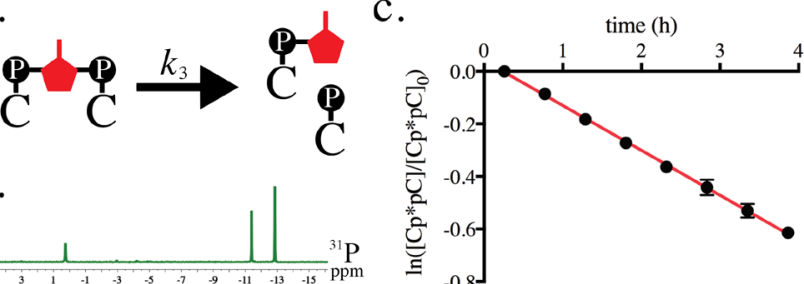

Figure 3. Intermediate $\mathrm{Cp} * \mathrm{pC}$ hydrolyzes to $\mathrm{Cp}^{*}$ and $\mathrm{Cp}$. (a) Schematic of the reaction measured to determine $k_{3}$. (b) ${ }^{31} \mathrm{P}$ NMR spectrum of $5 \mathrm{mM} \mathrm{Cp}{ }^{*} \mathrm{pC}$ incubated in primer extension buffer for 3.9 h. The peak at $0.28 \mathrm{ppm}$ corresponds to $\mathrm{Cp}$, that at $-11.41 \mathrm{ppm}$ to $\mathrm{Cp}^{*}$, and that at $-12.86 \mathrm{ppm}$ to $\mathrm{Cp}^{*} \mathrm{pC}$. (c) Quantification of hydrolysis in a first-order kinetic plot. The negative slope is equal to $k_{3}$ $=0.171 \pm 0.006 \mathrm{~h}^{-1}$. Error bars indicate $\pm \mathrm{SD}(n=3)$.

recorded every $31 \mathrm{~min}$ for $4.1 \mathrm{~h}$ (Figure $3 \mathrm{~b}$ ). In the absence of free $\mathrm{AI}$, the observed changes in concentration during this time frame should be entirely due to hydrolysis of $\mathrm{Cp}^{*} \mathrm{pC}$. As expected, the intermediate decayed to approximately equal amounts of $\mathrm{Cp}$ and $\mathrm{Cp}^{*}$, consistent with hydrolysis of $\mathrm{Cp}^{*} \mathrm{pC}$ (Figure S6). We calculated a pseudo-first-order rate constant of intermediate hydrolysis $\left[k_{3}=0.171 \pm 0.006 \mathrm{~h}^{-1}\right.$ (Figure 3c)]. This value corresponds to a half-life of $4.06 \pm 0.15 \mathrm{~h}$.

As a comparison to the traditional 2-methylimidazole activation, the hydrolysis rate of the 2-methylimidazoliumbridged dicytidine intermediate was also measured under similar reaction conditions (Figure S7). We used a partially purified 2-methylimidazolium intermediate as described in our previous report. ${ }^{10}$ The observed rate constant of hydrolysis for the 2-methylimidazolium intermediate was determined to be $4.40 \pm 0.07 \mathrm{~h}^{-1}$. This value is 26 times higher than the hydrolysis rate constant of 2 -aminoimidazolium $\mathrm{Cp}^{*} \mathrm{pC}$, indicating that 2 -aminoimidazolium $\mathrm{Cp}^{*} \mathrm{pC}$ is much more stable than the 2-methylimidazolium intermediate.

The $\mathrm{Cp}$ * Monomer Slowly Hydrolyzes to $\mathrm{Cp}$ and Al. We also measured the rate of hydrolysis of $\mathrm{Cp}^{*}$ in primer extension buffer (Figure 4a). Measuring the hydrolysis rate of

a.

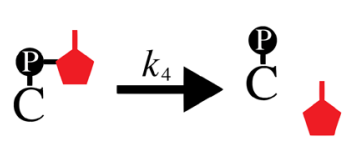

b.

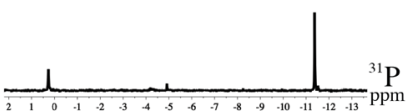

c.

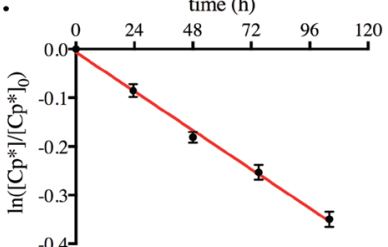

Figure 4. Monomer $\mathrm{Cp}^{*}$ decays slowly to $\mathrm{Cp}$ and AI. (a) Schematic of the reaction measured to determine $k_{4}$. (b) ${ }^{31} \mathrm{P}$ NMR spectrum of 5 $\mathrm{mM} \mathrm{Cp} *$ and $20 \mathrm{mM} \mathrm{AI}$ incubated in primer extension buffer for $72 \mathrm{~h}$. The peak at $0.29 \mathrm{ppm}$ corresponds to $\mathrm{Cp}$ and that at $-11.39 \mathrm{ppm}$ to $\mathrm{Cp}{ }^{*}$. The peak at $-4.92 \mathrm{ppm}$ corresponds to cyclic cytidine $3^{\prime}, 5^{\prime}$ monophosphate as verified by spike-in. (c) Hydrolysis of $5 \mathrm{mM} \mathrm{Cp} *$ in $40 \mathrm{mM}$ AI quantified by ${ }^{31} \mathrm{P}$ NMR spectra in a first-order rate plot. The negative slope is equal to $k_{4}=(3.33 \pm 0.03) \times 10^{-3} \mathrm{~h}^{-1}$. Error bars indicate $\pm \mathrm{SD}(n=3)$.

$\mathrm{Cp}^{*}$ was complex because $\mathrm{Cp}^{*}$ also self-reacts to form $\mathrm{Cp} * \mathrm{pC}$ (Figure 1), which can then hydrolyze to $\mathrm{Cp}$, the product of $\mathrm{Cp}^{*}$ hydrolysis. To minimize the concentration of $\mathrm{Cp}^{*} \mathrm{pC}$, the hydrolysis of $\mathrm{Cp}^{*}$ in primer extension buffer was measured at a series of concentrations of AI. We hypothesized that the excess $\mathrm{AI}$ would react with $\mathrm{Cp} * \mathrm{pC}$ to form two $\mathrm{Cp}^{*}$ molecules
(Figure 2), thereby reducing the $\mathrm{Cp} * \mathrm{pC}$ concentration without affecting $\mathrm{Cp}^{*}$ hydrolysis.

We began our analysis of the hydrolysis of $\mathrm{Cp}^{*}$ by recording ${ }^{31} \mathrm{P}$ NMR spectra of $5 \mathrm{mM} \mathrm{Cp} *$ and $20 \mathrm{mM}$ AI over 5 days. $\mathrm{Cp}^{*}$ gradually decayed into $\mathrm{Cp}$ as well as trace amounts of other products that were detected on the third day (Figure $4 \mathrm{~b}$ ). A peak corresponding to $\mathrm{Cp} * \mathrm{pC}$ was not observed, suggesting that $\mathrm{Cp}$ formed directly by hydrolysis of $\mathrm{Cp}^{*}$. In the presence of $20 \mathrm{mM} \mathrm{AI}$, we calculated the observed $\mathrm{Cp}^{*}$ hydrolysis rate constant $\left[k_{4}=(4.04 \pm 0.16) \times 10^{-3} \mathrm{~h}^{-1}\right]$.

Given that $k_{3}$ is $\sim 40$ times greater than $k_{4}$, our results could easily be affected by trace levels of $\mathrm{Cp}^{*} \mathrm{pC}$. We repeated our experiment using $40 \mathrm{mM} \mathrm{AI}$ and $5 \mathrm{mM} \mathrm{Cp} *$ in primer extension buffer. This time we observed that $k_{4}=(3.33 \pm 0.03)$ $\times 10^{-3} \mathrm{~h}^{-1}$ (Figure $4 \mathrm{c}$ ), suggesting that our previous results overestimated $k_{4}$ because of trace formation of $\mathrm{Cp}^{*} \mathrm{pC}$. Again, our experiments were repeated using $60 \mathrm{mM}$ AI. However, a precipitate was observed on the third day of the experiment, and these data were not analyzed. Overall, these results place an upper limit on the value of $k_{4}$ and suggest that the half-life of $\mathrm{Cp}^{*}$ is $>8.7$ days because of hydrolysis in primer extension buffer. In addition, we observed that the rate constant of 2MeImpC hydrolysis equals $(2.93 \pm 0.26) \times 10^{-3} \mathrm{~h}^{-1}$ under comparable conditions (Figure S8).

Cp*pC Is a Substrate for Primer Extension. Because $\mathrm{Cp}^{*} \mathrm{pC}$ both forms and decays in primer extension buffer, we began investigating how the concentration of $\mathrm{Cp}^{*} \mathrm{pC}$ affects the rate of primer extension. This relationship can be approximated through Michaelis-Menten kinetics because of the separate binding and reaction steps that occur on the primer-template complex. The primer-template complex is present at very low concentrations relative to those of substrates, which show saturation binding. ${ }^{19-21}$ In addition, Michaelis-Menten kinetics offers a framework for studying the effect of competitive inhibition on the polymerization rate (Figure 5a).

We determined the rate of primer extension using five concentrations of $\mathrm{Cp}^{*} \mathrm{pC}$ from 0.5 to $20 \mathrm{mM}$. We observed that the pseudo-first-order rate constant of polymerization during the first $3 \mathrm{~min}, k_{\mathrm{obs}}$ increased with the concentration of

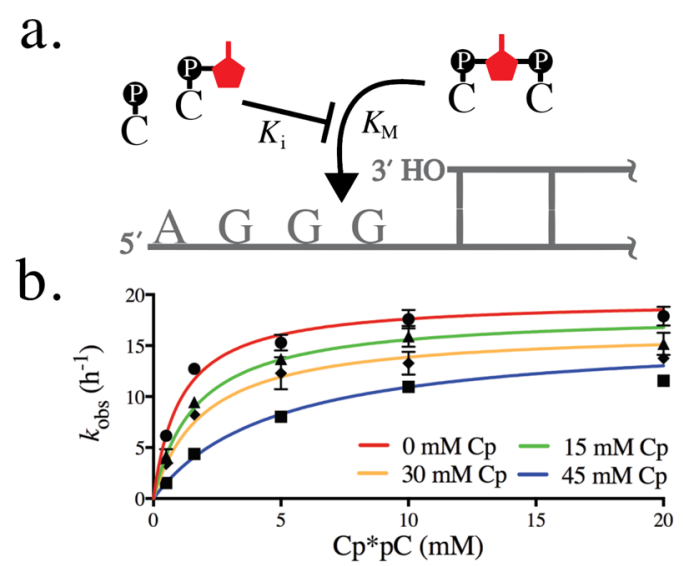

Figure 5. Cp competitively inhibits primer extension by $\mathrm{Cp}^{*} \mathrm{pC}$. (a) During the primer extension reaction, $\mathrm{Cp}^{*} \mathrm{pC}$ binds the template with an affinity related to the $K_{\mathrm{M}}$. The $\mathrm{Cp}$ and $\mathrm{Cp} *$ monomers also bind the template and competitively inhibit the primer extension reaction. (b) Michaelis-Menten plot of $\mathrm{Cp} \mathrm{p}^{*} \mathrm{pC}$ with $0-45 \mathrm{mM} \mathrm{Cp}$. Lines represent the Michaelis-Menten equation evaluated with empirical determinations of $k_{\mathrm{obsmax}}$ and effective $K_{\mathrm{M}}$. Error bars indicate $\pm \mathrm{SD}(n=3)$. 
the intermediate (Figure S9). $k_{\mathrm{obs}}$ plateaus at $\mathrm{Cp} * \mathrm{pC}$ concentrations above $5 \mathrm{mM}$, suggesting that the template becomes saturated by $\mathrm{Cp} * \mathrm{pC}$ binding (Figure $5 \mathrm{~b}$, red line). We analyzed these data using a double-reciprocal plot and substituted $V_{\max }$ with $k_{\mathrm{obsmax}}$ for the purpose of comparison. For primer extension by $\mathrm{Cp}^{*} \mathrm{pC}$ in the absence of competitive inhibition, we observed that $k_{\mathrm{obsmax}}=19.5 \pm 2.1 \mathrm{~h}^{-1}$ and $K_{\mathrm{M}}=$ $1.06 \pm 0.12 \mathrm{mM}$.

Having determined that $\mathrm{Cp} * \mathrm{pC}$ is a substrate of the primer extension reaction, we next analyzed how the monomer competitively inhibits primer extension by $\mathrm{Cp}^{*} \mathrm{pC}$. We repeated our Michaelis-Menten analysis of $\mathrm{Cp}^{*} \mathrm{pC}$ in the presence of $15-45 \mathrm{mM} \mathrm{Cp}$ and observed increasingly lower rates for this set of reactions compared to the set with $0 \mathrm{mM}$ $\mathrm{Cp}$ (Figure $5 \mathrm{~b}$ ). Overall, this set of data is consistent with competitive inhibition as analyzed by a double-reciprocal plot (Figure S10). As expected, the effective $K_{\mathrm{M}}$ increases with $\mathrm{Cp}$ concentration. On the basis of these values, we calculated that the $K_{\mathrm{i}}$ of $\mathrm{Cp}$ inhibition of primer extension by $\mathrm{Cp}^{*} \mathrm{pC}$ is $24.7 \pm$ $11.6 \mathrm{mM}$. This value agrees with the $K_{\mathrm{d}}$ of $15-19 \mathrm{mM}$ of $\mathrm{Cp}$ measured for a different RNA duplex. ${ }^{20}$ In addition, this value is consistent with the $K_{\mathrm{d}}$ of $19 \mathrm{mM}$ for $\mathrm{Cp}$ and the $K_{\mathrm{d}}$ of $27 \mathrm{mM}$ for 2-MeImpC previously determined for an RNA hairpin. ${ }^{21}$

We also note that our calculated $k_{\text {obsmax }}$ slightly decreases at higher concentrations of $\mathrm{Cp}$, suggesting possible mixed inhibition. However, we cannot fully exclude potential nonspecific effects of adding $\mathrm{Cp}$, such as changing the ionic strength of the primer extension reaction. In total, the data indicate that $k_{\mathrm{obsmax}}=17.6 \pm 1.6 \mathrm{~h}^{-1}$, which is within error of our values obtained with both $0 \mathrm{mM} \mathrm{Cp}$ and $45 \mathrm{mM} \mathrm{Cp}$.

Cp* Does Not Discernibly Contribute to the Primer Extension Rate. We next sought to determine the rate of primer extension by $\mathrm{Cp}^{*}$ directly reacting with the primer. The interpretation of these experiments is complicated by the fact that $\mathrm{Cp}^{*}$ forms $\mathrm{Cp} * \mathrm{pC}$ under primer extension conditions (Figure 1). However, we have quantified $\mathrm{Cp}^{*} \mathrm{pC}$ formation and the rate of primer extension by $\mathrm{Cp}^{*} \mathrm{pC}$ via competitive inhibition (Figure 5). Therefore, we can account for the rate of primer extension due to $\mathrm{Cp}^{*} \mathrm{pC}$ and then determine the rate due to $\mathrm{Cp}^{*}$, including possible noncovalent interactions between template-bound $\mathrm{Cp}^{*}$. We decided on a final $\mathrm{Cp}^{*}$ concentration of $30 \mathrm{mM}$ for these experiments to be above the $K_{\mathrm{d}}$ of the monomer, but not too high to limit Cp* $\mathrm{pC}$ formation at short time intervals.

The primer extension assay was initiated by adding a $45 \mathrm{mM}$ $\mathrm{Cp}^{*}$ stock at $\mathrm{pH} 9.6$ to a reaction mix for final concentrations of $30 \mathrm{mM} \mathrm{Cp} *, 90 \mathrm{mM}$ Tris, $90 \mathrm{mM} \mathrm{MgCl}, 2 \mu \mathrm{M}$ primer, and $3 \mu \mathrm{M}$ template, identical to our analysis of $\mathrm{Cp}^{*} \mathrm{pC}$. We observed the reaction over the first $8 \mathrm{~min}$, during which time the reaction rate noticeably increased, likely because of the formation of $\mathrm{Cp}^{*} \mathrm{pC}$ (Figure 6a). A similar phenomenon has been reported for primer extension by 2-MeImpG. ${ }^{10}$ Because of this "speed-up" effect, the calculated rate of primer extension is only approximated by pseudo-first-order kinetic plots. For the first $3 \mathrm{~min}$ of the primer extension time course, we observed that the initial rate constant of primer extension $k_{\mathrm{obs}}=0.93 \pm$ $0.11 \mathrm{~h}^{-1}$. In comparison, $k_{\mathrm{obs}}=2.6 \pm 0.5 \mathrm{~h}^{-1}$ for the last $3 \mathrm{~min}$ of this time course.

To account for the primer extension rate due to $\mathrm{Cp}^{*} \mathrm{pC}$, we first calculated the concentration of $\mathrm{Cp}^{*} \mathrm{pC}$ using the previously determined $k_{1}$. On the basis of this value, we expect an average concentration of $65 \pm 3 \mu \mathrm{M} \mathrm{Cp} * \mathrm{pC}$ over the first 3 min of the primer extension reaction. By using the $K_{\mathrm{M}}$ and $K_{\mathrm{i}}$

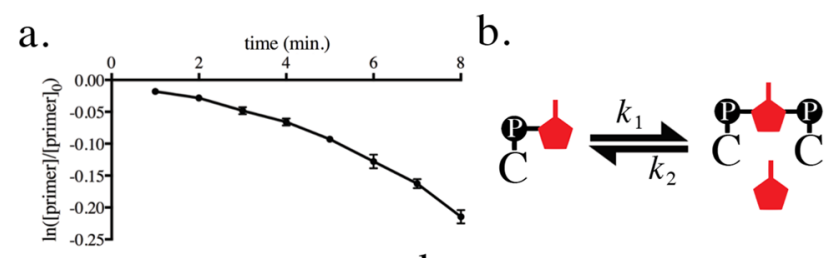

C.

d.

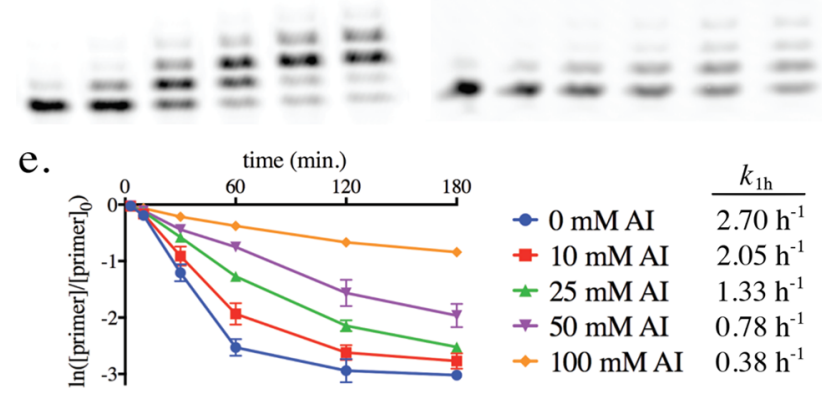

Figure 6. Primer extension in the presence of $\mathrm{Cp} *$ is largely due to the formation of $\mathrm{Cp}^{*} \mathrm{pC}$. (a) Pseudo-first-order plot of primer extension initiated by the $\mathrm{Cp}^{*}$ stock at $\mathrm{pH}$ 9.6. (b) Schematic illustrating that addition of AI favors $\mathrm{Cp}^{*}$ at the expense of $\mathrm{Cp}^{*} \mathrm{pC}$. (c) Gel image of nonenzymatic RNA primer extension with $20 \mathrm{mM} \mathrm{Cp} *$ and no additional AI. Samples are at 3, 10, 30, 60, 120, and 180 min. (d) Gel image of nonenzymatic RNA primer extension with $20 \mathrm{mM} \mathrm{Cp} *$ and $100 \mathrm{mM}$ AI. (e) Pseudo-first-order plot of nonenzymatic RNA primer extension with various concentrations of AI. The observed values of rate constant $k_{1 \mathrm{~h}}$ are recorded in the key. Error bars indicate $\pm \mathrm{SD}(n=$ $3)$.

values previously obtained and propagating the errors, we approximate that the $k_{\text {obs }}$ due to $\mathrm{Cp}^{*} \mathrm{pC}$ is $\approx 0.47 \pm 0.13 \mathrm{~h}^{-1}$. This calculation suggests that part of the observed rate may be due to $\mathrm{Cp}^{*}$ directly extending the primer. However, a low initial concentration of $\mathrm{Cp}^{*} \mathrm{pC}$ in our $\mathrm{Cp}^{*}$ stock at $\mathrm{pH} 9.6$ could explain the discrepancy. We repeated our calculations for the 6-8 min interval and computed a $k_{\text {obs }}$ of $2.0 \pm 0.5 \mathrm{~h}^{-1}$, which is within error of the observed value.

We sought another approach to directly measure primer extension by $\mathrm{Cp}^{*}$ by reducing the $\mathrm{Cp} * \mathrm{pC}$ concentration. Previously, excess AI was used to decrease the concentration of $\mathrm{Cp} * \mathrm{pC}$ in $\mathrm{Cp}^{*}$ solutions when studying hydrolysis (Figures 4 and $6 \mathrm{~b}$ ). We adopted a similar approach by adding $0-100 \mathrm{mM}$ $\mathrm{AI}$ to a series of primer extension reaction mixtures containing a final $\mathrm{Cp}^{*}$ concentration of $20 \mathrm{mM}$. Because of the low rates, we observed the primer extension reactions for $3 \mathrm{~h}$. In addition, we used $100 \mathrm{mM} \mathrm{MgCl}$ and $100 \mathrm{mM}$ Tris.

Addition of AI greatly inhibited the primer extension reaction (Figure $6 \mathrm{c}, \mathrm{d}$ ). For this set of experiments, we compared a pseudo-first-order rate constant calculated from the first hour of the primer extension reaction, $k_{1 \mathrm{~h}}$. For $0 \mathrm{mM} \mathrm{AI}$, we observed that $k_{1 \mathrm{~h}}=2.70 \mathrm{~h}^{-1}$. At $100 \mathrm{mM} \mathrm{AI}$, we observed that $k_{1 \mathrm{~h}}=0.38$ $\mathrm{h}^{-1}$. Notably, the rate markedly declines between 50 and 100 $\mathrm{mM} \mathrm{AI}$, suggesting that our observed rate constant is an upper limit to the polymerization rate of $\mathrm{Cp}^{*}$.

From these data, we extrapolated the primer extension rate to infinitely high concentrations of $\mathrm{AI}$, or when the $\mathrm{Cp}^{*} \mathrm{pC}$ concentration is zero. For the purpose of this calculation, we assumed that $\mathrm{Cp}^{*}$ is in equilibrium with $\mathrm{Cp} * \mathrm{pC}$ and $\mathrm{AI}$ (Figure 6b). To estimate the equilibrium constant, we noted that $K_{\text {eq }}=$ $k_{1} / k_{2}=0.019 \pm 0.004$ (Figure S11). Because $K_{\mathrm{eq}}=$ $\left[\mathrm{Cp}^{*} \mathrm{pC}\right][\mathrm{AI}]\left[\mathrm{Cp}^{*}\right]^{-2},[\mathrm{AI}]$ is reciprocal to $\left[\mathrm{Cp}^{*} \mathrm{pC}\right]$, and this equation can be used to approximate the concentration of 
$\mathrm{Cp} * \mathrm{pC}$ when $[\mathrm{AI}]$ is varied. The $k_{1 \mathrm{~h}}$ values were plotted versus the approximated $\left[\mathrm{Cp} \mathrm{p}^{*} \mathrm{pC}\right]$ values in a Michaelis-Menten plot (Figure S12). We then analyzed this plot using nonlinear regression to a Michaelis-Menten equation modified with a constant term to represent the possible reaction rate due to 20 $\mathrm{mM} \mathrm{Cp}{ }^{*}$. We observed that the $y$-intercept, when $\left[\mathrm{Cp}^{*} \mathrm{pC}\right]$ is zero, is equal to $-0.286 \pm 0.159 \mathrm{~h}^{-1}$ standard error. This negative value of $k_{1 \mathrm{~h}}$ is likely due to an overestimation of [Cp*pC] from the $K_{\mathrm{eq}}$ value, because $\mathrm{Cp} \mathrm{p}^{*} \mathrm{pC}$ also hydrolyzes. However, our analysis suggests that the contribution of $\mathrm{Cp}^{*}$ to the primer extension rate is indistinguishable from zero under these conditions.

Kinetic Modeling of the Primer Extension Reaction. We sought to combine our kinetic data into a kinetic model to develop and test our understanding of the primer extension reaction. The model needed to explain both the concentration of the intermediate formed over time under primer extension conditions and how this affects the rate of polymerization. We reasoned that solutions of $\mathrm{Cp}^{*}$ would undergo a series of offtemplate reactions involving $\mathrm{Cp} * \mathrm{pC}, \mathrm{AI}$, and $\mathrm{Cp}$ (Scheme 1).

Scheme 1. Kinetic Model of Primer Extension by $\mathrm{Cp}^{*^{a}}$

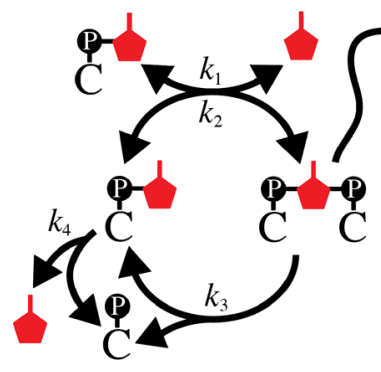

off-template

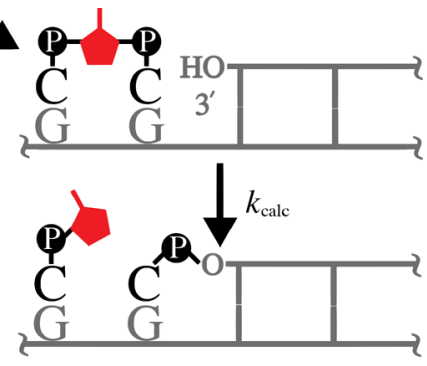

template-directed
${ }^{a} \mathrm{On}$ the left, the off-template reactions form and destroy $\mathrm{Cp}^{*}$ and $\mathrm{Cp}$ *pC. $\mathrm{Cp}$ is formed as a hydrolysis product. On the right, the primer is extended by only $\mathrm{Cp}^{*} \mathrm{pC}$. Primer extension is also competitively inhibited by $\mathrm{Cp}^{*}$ and $\mathrm{Cp}$.

Only intermediate $\mathrm{Cp} * \mathrm{pC}$ binds the template and subsequently reacts with the primer. As observed in our analysis of inhibition by $\mathrm{AI}$, the reaction of $\mathrm{Cp}^{*}$ with the primer is too slow to significantly affect the rate of polymerization (Figure 6). Finally, we assume that the concentrations of $\mathrm{AI}, \mathrm{Cp}, \mathrm{Cp}^{*}$, and $\mathrm{Cp}^{*} \mathrm{pC}$ are not greatly affected by the primer-template duplex on short time scales.

We modeled the four off-template reactions using four kinetic rate equations to describe how the concentration of each molecule will change over time.

$$
\begin{aligned}
& \mathrm{d}[\mathrm{Cp} *] / \mathrm{d} t=-2 k_{1}\left[\mathrm{Cp}^{*}\right]^{2}+2 k_{2}[\mathrm{Cp} * \mathrm{pC}][\mathrm{AI}] \\
&+ k_{3}[\mathrm{Cp} * \mathrm{pC}]-k_{4}[\mathrm{Cp} *] \\
& \mathrm{d}[\mathrm{Cp} * \mathrm{pC}] / \mathrm{d} t= k_{1}[\mathrm{Cp}]^{2}-k_{2}[\mathrm{Cp} * \mathrm{pC}][\mathrm{AI}] \\
&-k_{3}[\mathrm{Cp} * \mathrm{pC}] \\
& \mathrm{d}[\mathrm{Cp}] / \mathrm{d} t=k_{3}[\mathrm{Cp} * \mathrm{pC}]+k_{4}[\mathrm{Cp} *] \\
& \mathrm{d}[\mathrm{AI}] / \mathrm{d} t=k_{1}\left[\mathrm{Cp}^{*}\right]^{2}-k_{2}[\mathrm{Cp} * \mathrm{pC}][\mathrm{AI}]+k_{4}\left[\mathrm{Cp}^{*}\right]
\end{aligned}
$$

In these equations, rate constants $k_{1}-k_{4}$ correspond to the reactions studied by ${ }^{31} \mathrm{P}$ NMR (Figures $1-4$ and Table 1). By iteratively solving these equations following initial conditions, we can model the concentrations of all four molecules over time.

Table 1. Off-Template Reaction Rate Constants \pm SD Observed Experimentally (Figures 1-4) or Computationally Fit to $24 \mathrm{mM} \mathrm{Cp}$ * Solutions (Figure 7)

\begin{tabular}{lll} 
& \multicolumn{1}{c}{ observed } & \multicolumn{1}{c}{ fitted } \\
$k_{1}\left(\mathrm{~h}^{-1} \mathrm{mM}^{-1}\right)$ & $(4.49 \pm 0.47) \times 10^{-3}$ & $(4.55 \pm 0.48) \times 10^{-3}$ \\
$k_{2}\left(\mathrm{~h}^{-1} \mathrm{mM}^{-1}\right)$ & $0.238 \pm 0.020$ & $0.183 \pm 0.026$ \\
$k_{3}\left(\mathrm{~h}^{-1}\right)$ & $0.171 \pm 0.006$ & $0.167 \pm 0.012$ \\
$k_{4}\left(\mathrm{~h}^{-1}\right)$ & $(3.33 \pm 0.03) \times 10^{-3}$ & $(2.11 \pm 0.84) \times 10^{-3}$
\end{tabular}

We modeled the rate of the primer extension reaction based on our Michaelis-Menten kinetic analysis of primer extension by $\mathrm{Cp}^{*} \mathrm{pC}$ (Figure 5). The rate constant of polymerization can be calculated using the relationship

$$
\begin{aligned}
& k_{\text {calc }}=k_{\text {obsmax }}\left[\mathrm{Cp}^{*} \mathrm{pC}\right] /\left(K_{\mathrm{eff}}+\left[\mathrm{Cp}^{*} \mathrm{pC}\right]\right) \\
& K_{\text {eff }}=K_{\mathrm{M}}\left[1+\left([\mathrm{Cp}]+\left[\mathrm{Cp}^{*}\right]\right) / K_{\mathrm{i}}\right]
\end{aligned}
$$

where $k_{\text {obsmax }}, K_{\mathrm{M}}$, and $K_{\mathrm{i}}$ are empirically determined constants (Figure 5). These equations combine the Michaelis-Menten equation with competitive inhibition by the monomers, $\mathrm{Cp}$ and $C \mathrm{p}^{*}$. Under our reaction conditions, both $\mathrm{Cp}$ and $\mathrm{Cp} \mathrm{p}^{*}$ are assumed to bind the template with approximately equal affinity to competitively inhibit primer extension. Using the calculated concentrations of $\mathrm{Cp}, \mathrm{Cp}^{*}$, and $\mathrm{Cp}^{*} \mathrm{pC}$ (eqs 1-4) to evaluate $k_{\text {calc }}$ (eqs 5and 6), we can model how the polymerization rate of nonenzymatic primer extension changes over time due to the off-template reactions.

Analyzing Long-Term Behavior of Off-Template Reactions with the Kinetic Model. We first tested our kinetic model of the off-template reactions against experimental data obtained by ${ }^{31} \mathrm{P}$ NMR (Figure 7). Beginning with $24 \mathrm{mM}$ $\mathrm{Cp}^{*}$ in primer extension buffer, we observed the concentrations of $\mathrm{Cp}, \mathrm{Cp}^{*}$, and $\mathrm{Cp}^{*} \mathrm{pC}$ every $7 \mathrm{~min}$ and $44 \mathrm{~s}$ for $12.5 \mathrm{~h}$.
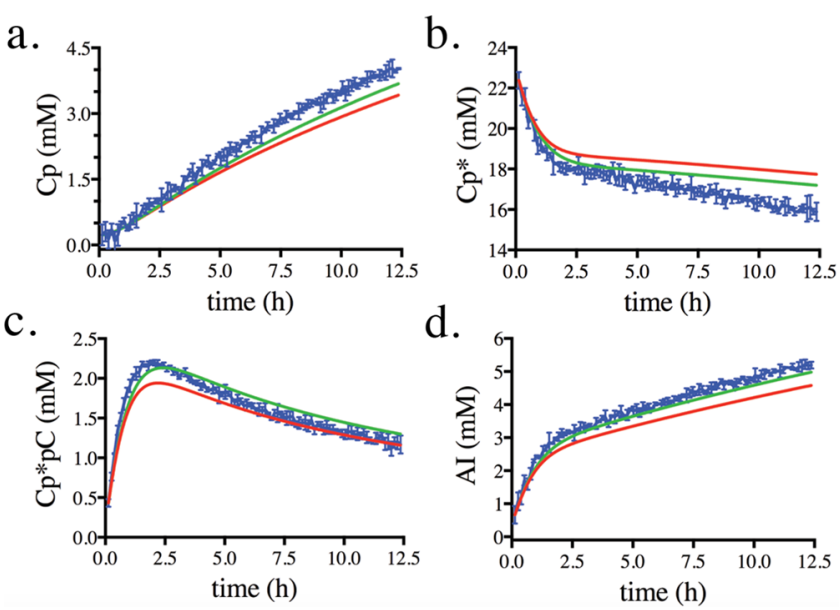

Figure 7. Kinetic model describing the long-term behavior of offtemplate reactions in $24 \mathrm{mM} \mathrm{Cp}$ * solutions in primer extension buffer. Concentrations over time for experimentally observed (blue), empirical model (red), and fitted model (green) are presented for (a) $\mathrm{Cp}$, (b) $\mathrm{Cp}^{*}$, (c) $\mathrm{Cp}^{*} \mathrm{pC}$, and (d) AI. Concentrations were experimentally determined using ${ }^{31} \mathrm{P}$ NMR. Modeled concentrations were iteratively calculated using eqs $1-4$ and the rate constants listed in Table 1. 
Because AI cannot be observed by ${ }^{31} \mathrm{P}$ NMR, we inferred that the concentration of $\mathrm{AI}$ is equal to the concentration of $\mathrm{Cp}$ plus $\mathrm{Cp} * \mathrm{pC}$.

Our experimental observations of off-template reactions displayed dynamic changes in concentration for some of the molecules. For $\mathrm{Cp}$, the concentration steadily increased over time from 0.2 to $4.0 \mathrm{mM}$ over $12.5 \mathrm{~h}$ (Figure $7 \mathrm{a}$, blue line). In contrast, the concentration of $\mathrm{Cp}^{*}$ rapidly decreased from 22.4 to $18.0 \mathrm{mM}$ over the first $2 \mathrm{~h}$ and then slowly decreased to 15.9 $\mathrm{mM}$ over the next $10.5 \mathrm{~h}$ (Figure $7 \mathrm{~b}$, blue line). For $\mathrm{Cp}^{*} \mathrm{pC}$, we observed a sharp increase over the first $2 \mathrm{~h}$ from 0.4 to $2.2 \mathrm{mM}$ (Figure $7 \mathrm{c}$, blue line). At this peak concentration, $\mathrm{Cp}^{*} \mathrm{pC}$ accounts for $18 \%$ of the cytidine present in the mixture. Over the next $10.5 \mathrm{~h}$, the concentration of $\mathrm{Cp}^{*} \mathrm{pC}$ gradually decreases to $1.2 \mathrm{mM}$. Finally, the AI concentration was inferred to sharply increase during the first $2 \mathrm{~h}$ from 0.7 to $3.1 \mathrm{mM}$ and then gradually increase to $5.2 \mathrm{mM}$ by the end of the NMR series (Figure $7 \mathrm{~d}$, blue line). In addition, we also observed four peaks from trace products (Figure S13).

We compared these data to our kinetic model initialized with the concentrations observed in the first spectrum of the NMR series and a step size of $1 \mathrm{~min}$ for $\mathrm{d} t$ in our calculations. Overall, we observed similar trends between our model and the experimental observations of the four molecules (Figure 7, red lines). For $\mathrm{Cp}^{*}, \mathrm{Cp} * \mathrm{pC}$, and $\mathrm{AI}$, the model predicts a $2 \mathrm{~h}$ initial phase of rapid concentration change, followed by a second phase of gradual changes. However, there are important discrepancies between the model and the experimental data. Most notable is the $14 \%$ difference between the calculated and observed concentrations of $\mathrm{Cp}$ at the end of the time course (Figure 7a). This may be due in part to the $12 \%$ underestimation of $\mathrm{Cp}^{*} \mathrm{pC}$ at its peak concentration near $2 \mathrm{~h}$ (Figure 7c). In addition, a $1.9 \mathrm{mM}$ difference develops between the model and the observed concentration of $\mathrm{Cp}^{*}$ (Figure $7 \mathrm{~b}$ ). Part of this discrepancy is likely due to the formation of trace materials that amount to $\sim 1.8 \mathrm{mM}$ by $12.5 \mathrm{~h}$. Future studies of the off-template reactions should account for the formation of these trace materials.

Given the differences between the model and the observed concentrations, we computationally fit the off-template $k$ values to this experimental data set. Our approach randomly varied $k$ values within $\pm 20 \%$ for 100 iterations and then computed the concentrations of all four molecules for $12.5 \mathrm{~h}$. The $k$ values were kept if they simultaneously improved the square of normalized residuals for all of the molecules. As our input $k$ values for the first iteration, we used the experimentally determined $k$ values randomly multiplied or divided by up to 2 times.

We repeated this calculation 100 times and then averaged the fitted $k$ parameters (Table 1 ). As expected, the fitted $k$ values improve our agreement between the kinetic model and experimental observations (Figure 7, green lines). In general, the fitted $k$ values agree with our experimental determinations of $k_{1}$ and $k_{3}$ but significantly differ from our determinations of $k_{2}$ and $k_{4}$ (Table 1). Notably, this analysis suggests that we systematically overestimated rate constant $k_{2}$, which caused our empirical model to underestimate the level of $\mathrm{Cp} * \mathrm{pC}$ and subsequently underestimate the levels of $\mathrm{Cp}$ and AI.

The Kinetic Model Explains the Rate of Primer Extension at Early Times. Next, we compared our predicted $k_{\text {calc }}$ against the experimentally determined $k_{\text {obs }}$ of primer extension reactions over time. To determine how the rate of polymerization changes over $10 \mathrm{~h}$, we incubated $24 \mathrm{mM} \mathrm{Cp} *$ in primer extension buffer and periodically removed aliquots to initiate primer extension reactions and determine $k_{\mathrm{obs}}$. After addition of $\mathrm{Cp}^{*}$, the primer extension mixture contains $90 \mathrm{mM}$ $\mathrm{MgCl}_{2}$ and $90 \mathrm{mM}$ Tris, which is identical to the conditions of our $K_{\mathrm{M}}$ determination (Figure 5).

We observed that the change in the $k_{\text {obs }}$ of primer extension displayed two stages (Figure $8 \mathrm{a}$ ). In the first $2 \mathrm{~h}$, the $k_{\mathrm{obs}}$ of

a.

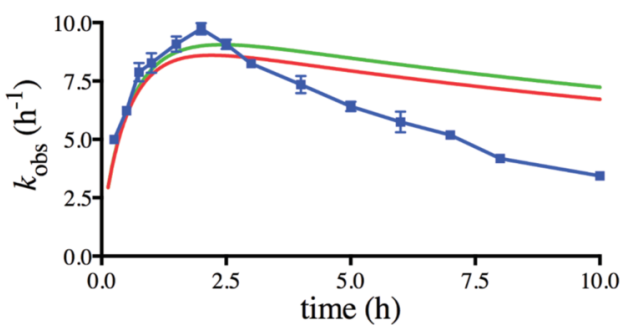

b.

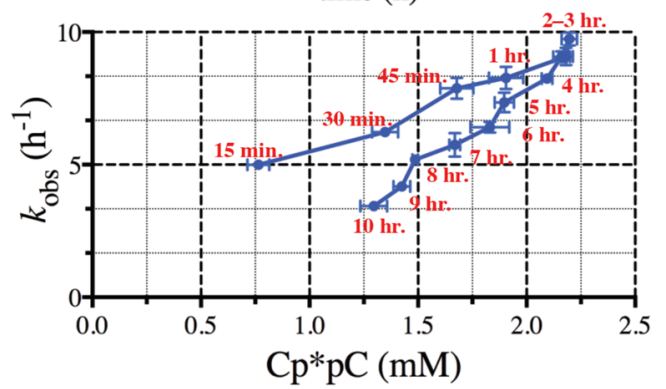

Figure 8. $k_{\text {obs }}$ drifts lower than $k_{\text {calc }}$ over long-term primer extension experiments. (a) A $24 \mathrm{mM} \mathrm{Cp}$ * solution incubated in primer extension buffer is used to initiate primer extension reactions at various times to obtain $k_{\text {obs }}$ (blue). $k_{\text {calc }}$ is obtained by evaluating eqs 5 and 6 with concentrations calculated using the empirically determined (red) or computationally fit (green) rate constants of the off-template reactions. (b) Experimentally determined $k_{\mathrm{obs}}$ values of primer extension are plotted vs the concentration of $\mathrm{Cp} * \mathrm{pC}$ observed by ${ }^{31} \mathrm{P}$ NMR

primer extension increases from 5.0 to $9.7 \mathrm{~h}^{-1}$. Subsequently, $k_{\text {obs }}$ steadily declines to $3.4 \mathrm{~h}^{-1}$ after incubation for $10 \mathrm{~h}$ in primer extension buffer. On the basis of our model using either the empirical or fitted off-template parameters listed in Table 1, the change in $k_{\text {calc }}$ also displayed two stages over $10 \mathrm{~h}$. For the fitted parameters, $k_{\text {calc }}$ increases during the first $2 \mathrm{~h}$ from 2.9 to $9.0 \mathrm{~h}^{-1}$ and then gradually decreases to $7.2 \mathrm{~h}^{-1}$ by the end of the time course (Figure 8a, green line). By comparing $k_{\text {calc }}$ with $k_{\text {obs }}$, we observed that this model agrees with observation for the first $2 \mathrm{~h}$ but subsequently overestimates the polymerization rate for the next $8 \mathrm{~h}$. The difference between $k_{\text {calc }}$ and $k_{\text {obs }}$ grows over time and cannot be explained by a difference between observed and calculated concentrations. These results indicate that the decline in $k_{\mathrm{obs}}$ is not fully explained by $\mathrm{Cp}^{*} \mathrm{pC}$ polymerization and competitive inhibition by monomers $\mathrm{Cp}$ and $\mathrm{Cp}^{*}$

To better understand the reasons why the model does not fully explain the rate of primer extension, we analyzed a plot of $k_{\text {obs }}$ versus the concentration of $\mathrm{Cp} * \mathrm{pC}$ observed by ${ }^{31} \mathrm{P}$ NMR (Figure $8 \mathrm{~b}$ ). This plot was obtained by combining the data from Figures $7 \mathrm{c}$ and $8 \mathrm{a}$ and eliminating the time variable. We observed a positive correlation between $k_{\mathrm{obs}}$ and the concentration of the intermediate (Pearson $r=0.836$, and two-tailed $p<0.0002$ ), suggesting that the concentration of $\mathrm{Cp}^{*} \mathrm{pC}$ is a key factor that determines the polymerization rate. In addition, we noticed that the later time points generally 
displayed a value for $k_{\text {obs }}$ lower than those of earlier time points. For instance, the observed concentration of Cp* $\mathrm{pC}$ at both 30 $\mathrm{min}$ and $10 \mathrm{~h}$ is $1.3 \mathrm{mM}$. However, $k_{\mathrm{obs}}=6.2 \mathrm{~h}^{-1}$ at $30 \mathrm{~min}$, and $k_{\mathrm{obs}}=3.4 \mathrm{~h}^{-1}$ at $10 \mathrm{~h}$. These results suggest that an additional factor is changing over time to decrease the rate of primer extension. We hypothesize that trace amounts of potent inhibitors, possibly short oligomers, may accumulate over time. Alternatively, hydrolysis products $\mathrm{AI}$ and $\mathrm{Cp}$ might inhibit primer extension in ways not represented by our analysis. Future improvement of the kinetic model should identify and analyze the cause of decreased rates in long-term experiments.

\section{CONCLUSIONS}

We have provided a kinetic model that recapitulates several features of the primer extension reaction over time and establishes that the predominant mechanism of nonenzymatic RNA polymerization of cytidine-5' -phosphoro-2-aminoimidazolide involves reaction of the primer with $\mathrm{Cp}^{*} \mathrm{pC}$. Although we cannot entirely exclude the traditional mechanism of a nucleophilic attack from the primer on $\mathrm{Cp}^{*}$, the contribution of this proposed mechanism to the reaction rate is negligible $(<0.4$ $\mathrm{h}^{-1}$ ) under these conditions. This is likely due to the enhanced reactivity of $\mathrm{Cp}^{*} \mathrm{pC}$ relative to $\mathrm{Cp}^{*}$, as well as the higher affinity of the dinucleotide intermediate for the template. In addition, the alternative mechanism of a downstream monomer mediating a noncovalent "leaving group-leaving group" interaction under these conditions is unlikely based upon measured binding affinities and analogue studies. ${ }^{12,13}$

Although this study clarifies the chemical mechanism of polymerization solely using monomers, the effect of downstream oligomers on the mechanism remains to be investigated. Possibly, noncovalent interactions occur using a stably bound downstream oligomer activated with AI. In addition, we have yet to explicitly investigate the catalysis of $\mathrm{Cp}^{*} \mathrm{pC}$ formation by a complementary template. Previous reports indicate that complementary oligonucleotides act as a template for the reaction between 2-methylimidazole-activated monomers and ribonucleotide $5^{\prime}$-monophosphates to form dinucleotide $5^{\prime}, 5^{\prime}$ pyrophosphates. $^{22,23}$ This work suggests that two templatebound $\mathrm{Cp}^{*}$ might locally react to form $\mathrm{Cp}^{*} \mathrm{pC}$ and then polymerize. $^{24}$

The differences between the kinetic model and the experimental observations identify gaps in our understanding of nonenzymatic RNA polymerization. First, the kinetic model does not include the formation of the trace materials observed after extended incubation in primer extension buffer. Second, the rate of polymerization decreases more quickly than our model predicts. This leads us to speculate that these trace compounds might be the inhibitors that explain why the polymerization rate decreases more quickly than expected. However, we note that the potential formation of inhibitors may be a peculiarity of the specific reaction system we have studied. Future extensions of the kinetic model should address additional, more complex systems, including multiple monomers and mixed-template sequences.

Lastly, our results address the reasons why 5 -phosphoro-2aminoimidazole activation outperforms that of 2-methylimidazole. When we incubated $24 \mathrm{mM}$ 2-MeImpC in primer extension buffer, we did not observe detectable levels of the corresponding 2-methylimidazolium-bridged dinucleotide by ${ }^{31} \mathrm{P}$ NMR (Figure S14). Because it is readily detectable at lower $\mathrm{pH}$, we hypothesize that it is present at low concentrations. ${ }^{10}$ We suspect two reasons for the accumulation of the 2- aminoimidazolium $\mathrm{Cp} * \mathrm{pC}$. First, the formation of the intermediate is $\mathrm{pH}$-dependent and is optimal when $\mathrm{pH}=$ $\mathrm{p} K_{\mathrm{a}}{ }^{10}$ The higher $\mathrm{p} K_{\mathrm{a}}$ of the 2 -aminoimidazole group is more favorable than 2-methylimidazole for formation of the intermediate at $\mathrm{pH} 8.3-8.4 .^{9}$ Second, the increased stability of the 2 -aminoimidazolium $\mathrm{Cp}^{*} \mathrm{pC}$ relative to the 2methylimidazolium dinucleotide also favors accumulation of this molecule under primer extension conditions (Figure 3 and Figure S7). We note that the 2-methylimidazolium intermediate was too reactive to effectively purify in our previous study, ${ }^{10}$ but we were readily able to synthesize the 2aminoimidazolium $\mathrm{Cp} * \mathrm{pC}$ with $>90 \%$ purity in this work. Unexpectedly, the hydrolysis rates of the 2-MeImpC and the 2amino $\mathrm{Cp}^{*}$ were very similar when free imidazole was used to limit formation of the intermediate (Figure 4 and Figure S8). This observation differs from a previous result suggesting that the 2-amino monomer hydrolyzes twice as fast as the 2-methyl monomer under primer extension conditions. ${ }^{9}$ Because of the comparable stabilities of these monomers, we suspect that the nucleophilicity of the imidazole group also plays an important role in the strongly enhanced reaction rate of 2 -aminoimidazole-activated monomers. Continuing investigations of the reaction mechanism will help to clarify the reasons for the superiority of 2-aminoimidazole and identify the reaction pathways that will need to be optimized to further improve nonenzymatic RNA polymerization.

\section{ASSOCIATED CONTENT}

\section{Supporting Information}

The Supporting Information is available free of charge on the ACS Publications website at DOI: 10.1021/acs.biochem.7b00792.

$$
\text { Supplementary Figures S1-S14 (PDF) }
$$

\section{AUTHOR INFORMATION}

\section{Corresponding Author}

*E-mail: szostak@molbio.mgh.harvard.edu. ORCID ${ }^{\circ}$

Travis Walton: 0000-0001-6812-1579

Jack W. Szostak: 0000-0003-4131-1203

\section{Author Contributions}

The manuscript was written through contributions of both authors. Both authors have given approval to the final version of the manuscript. T.W. designed and performed the experiments. J.W.S. designed the experiments.

\section{Funding}

J.W.S. is an Investigator of the Howard Hughes Medical Institute. This work was supported in part by National Science Foundation Grant CHE-1607034 to J.W.S. and a grant (290363) from the Simons Foundation to J.W.S.

\section{Notes}

The authors declare no competing financial interest.

\section{ACKNOWLEDGMENTS}

The authors acknowledge the helpful advice and assistance of Derek O’Flaherty, Chun Pong Tam, and Lydia Pazienza.

\section{ABBREVIATIONS}

2-MeImpC, cytidine-5' -phosphoro-2-methylimidazolide; 2MeImpG, guanosine-5'-phosphoro-2-methylimidazolide; AI, 2-aminoimidazole; $\mathrm{Cp}$, cytidine $5^{\prime}$-monophosphate; $\mathrm{Cp} *$, 
cytidine-5'-phosphoro-2-aminoimidazolide; Cp*pC, 1,3-di(cytidine-5'-phosphoro)-2-aminoimidazolium; SD, standard deviation.

\section{REFERENCES}

(1) Robertson, M. P., and Joyce, G. F. (2012) The origins of the RNA world. Cold Spring Harbor Perspect. Biol. 4, a003608.

(2) Hud, N. V., Cafferty, B. J., Krishnamurthy, R., and Williams, L. D. (2013) The origin of RNA and "my grandfather's axe". Chem. Biol. 20, 466-474.

(3) Orgel, L. E. (2004) Prebiotic chemistry and the origin of the RNA world. Crit. Rev. Biochem. Mol. Biol. 39, 99-123.

(4) Patel, B. H., Percivalle, C., Ritson, D. J., Duffy, C. D., and Sutherland, J. D. (2015) Common origins of RNA, protein and lipid precursors in a cyanosulfidic protometabolism. Nat. Chem. 7, 301307.

(5) Heuberger, B. D., Pal, A., Del Frate, F., Topkar, V. V., and Szostak, J. W. (2015) Replacing uridine with 2-thiouridine enhances the rate and fidelity of nonenzymatic RNA primer extension. J. Am. Chem. Soc. 137, 2769-2775.

(6) Larsen, A. T., Fahrenbach, A. C., Sheng, J., Pian, J., and Szostak, J. W. (2015) Thermodynamic insights into 2-thiouridine-enhanced RNA hybridization. Nucleic Acids Res. 43, 7675-7687.

(7) He, C., Gállego, I., Laughlin, B., Grover, M. A., and Hud, N. V. (2017) A viscous solvent enables information transfer from genelength nucleic acids in a model prebiotic replication cycle,. Nat. Chem. 9, 318-324.

(8) Prywes, N., Blain, J. C., Del Frate, F., and Szostak, J. W. (2016) Nonenzymatic copying of RNA templates containing all four letters is catalyzed by activated oligonucleotides. eLife 5, e17756.

(9) Li, L., Prywes, N., Tam, C. P., O’Flaherty, D. K., Lelyveld, V. S., Izgu, E. C., Pal, A., and Szostak, J. W. (2017) Enhanced nonenzymatic RNA copying with 2-aminoimidazole activated nucleotides. J. Am. Chem. Soc. 139, 1810-1813.

(10) Walton, T., and Szostak, J. W. (2016) A highly reactive imidazolium-bridged dinucleotide intermediate in nonenzymatic RNA primer extension,. J. Am. Chem. Soc. 138, 11996-12002.

(11) Wu, T., and Orgel, L. E. (1992) Nonenzymatic templatedirected synthesis on hairpin oligonucleotides. 2. Templates containing cytidine and guanosine residues. J. Am. Chem. Soc. 114, 5496-5501.

(12) Tam, C. P., Fahrenbach, A. C., Björkbom, A., Prywes, N., Izgu, E. C., and Szostak, J. W. (2017) Downstream oligonucleotides strongly enhance the affinity of GMP to RNA primer-template complexes. J. Am. Chem. Soc. 139, 571-574.

(13) Zhang, W., Tam, C. P., Wang, J., and Szostak, J. W. (2016) Unusual base-pairing interactions in monomer-template complexes. ACS Cent. Sci. 2, 916-926.

(14) Zhang, W., Tam, C. P., Walton, T., Fahrenbach, A. C., Birrane, G., and Szostak, J. W. (2017) Insight into the mechanism of nonenzymatic RNA primer extension from the structure of an RNAGpppG complex. Proc. Natl. Acad. Sci. U. S. A. 114, 7659-7664.

(15) Kanavarioti, A., Bernasconi, C. F., Doodokyan, D. L., and Alberas, D. J. (1989) Magnesium ion catalyzed P-N bond hydrolysis in imidazolide-activated nucleotides. Relevance to template-directed synthesis of polynucleotides. J. Am. Chem. Soc. 111, 7247-7257.

(16) Li, L., Lelyveld, V. S., Prywes, N., and Szostak, J. W. (2016) Experimental and computational evidence for a loose transition state in phosphoroimidazolide hydrolysis. J. Am. Chem. Soc. 138, 39863989.

(17) Kanavarioti, A., Bernasconi, C. F., Alberas, D. J., and Baird, E. E. (1993) Kinetic dissection of individual steps in the poly(C)-directed oligoguanylate synthesis from guanosine 5 -monophosphate 2methylimidazolide. J. Am. Chem. Soc. 115, 8537-8546.

(18) Kanavarioti, A., Bernasconi, C. F., and Baird, E. E. (1998) Effects of monomer and template concentration on the kinetics of nonenzymatic template-directed oligoguanylate synthesis. J. Am. Chem. Soc. $120,8575-8581$.
(19) Kervio, E., Claasen, B., Steiner, U. E., and Richert, C. (2014) The strength of the template effect attracting nucleotides to naked DNA,. Nucleic Acids Res. 42, 7409-7420.

(20) Izgu, E. C., Fahrenbach, A. C., Zhang, N., Li, L., Zhang, W., Larsen, A. T., Blain, J. C., and Szostak, J. W. (2015) Uncovering the thermodynamics of monomer binding for RNA replication. J. Am. Chem. Soc. 137, 6373-6382.

(21) Kervio, E., Sosson, M., and Richert, C. (2016) The effect of leaving groups on binding and reactivity in enzyme-free copying of DNA and RNA,. Nucleic Acids Res. 44, 5504-5514.

(22) Puthenvedu, D., Janas, T., Majerfeld, I., Illangasekare, M., and Yarus, M. (2015) Poly(U) RNA-templated synthesis of AppA. RNA $21,1818-1825$.

(23) Majerfeld, I., Puthenvedu, D., and Yarus, M. (2016) Crossbackbone templating; ribodinucleotides made on poly(C). RNA 22, 397-407.

(24) Wachowius, F., Attwater, J., and Holliger, P. (2017) Nucleic acids: function and potential for abiogenesis. Q. Rev. Biophys. 50, e4. 